\title{
Percepciones de los estudiantes, desde su diversidad, sobre los efectos de la transición a la modalidad en línea en el marco de la pandemia COVID-19
}

\author{
Ricardo Pérez-Mora (10) \\ Carlos Iván Moreno Arellano (1) \\ Universidad de Guadalajara (UDG), México
}

\begin{abstract}
Resumen. El estudio analiza algunos efectos en los estudiantes de la transición a la modalidad en línea en el marco de la pandemia. Parte de problematizar la manera en que el cierre de escuelas, el aislamiento social, y el conjunto de restricciones a la libertad de los estudiantes, trajo consigo profundos cambios en las formas de socialización e interacción humana, así como en el proceso de enseñanza aprendizaje, entre los destaca el cambio radical hacia la educación en línea. Se analizan algunos efectos de estas transformaciones en los estudiantes a través de un cuestionario aplicado en la Universidad de Guadalajara en dos periodos, julio 2020 y enero 2021. El análisis considera los impactos diferenciados en razón de la diversidad de los estudiantes a través de variables como género, nivel socioeconómico, situación laboral, dependientes económicos, discapacidades, pertenencia a pueblo indígena y estado civil. Entre los hallazgos encontramos que ciertos estudiantes, sufren más que otros los efectos del fenómeno, entre los que se encuentran las mujeres y los estudiantes con discapacidad. Pero también encontramos que ciertos estudiantes con responsabilidades laborales y familiares sufren en menor medida algunos de los efectos. Diferencias que creemos se deben considerar para pensar el futuro de la educación.
\end{abstract}

Palabras clave: estudiantes; pandemia; diversidad; educación superior; covid-19

Percepções dos estudantes, desde a sua diversidade, sobre os efeitos da transição à modalidade on-line no contexto da pandemia covid-19

Resumo. O estudo analisa alguns efeitos nos estudantes da transição à modalidade on-line no contexto da pandemia. Origina-se da problematização sobre a maneira em que o fechamento de escolas, o isolamento social e o conjunto de restrições à liberdade dos estudantes trouxe consigo profundas mudanças nas formas de socialização e interação humana, assim como no processo de ensino-aprendizagem, entre os quais destaca a mudança radical ao ensino on-line. Foram analisados alguns efeitos destas transformações nos estudantes através de um questionário aplicado na Universidad de Guadalajara em dois períodos, julho de 2020 e janeiro de 2021. A análise considera os impactos diferenciados em razão da diversidade dos estudantes através de variáveis como gênero, nível socioeconômico, situação laboral, dependentes econômicos, deficiências, pertencimento a povo indígena e estado civil. Estre as descobertas detectamos que certos estudantes sofrem mais do que outros os efeitos do fenômeno, entre os quais se encontram as mulheres e os estudantes com deficiência. Entretanto também detectamos que certos estudantes com responsabilidades de trabalho e familiares sofrem menos alguns dos efeitos. Diferenças que consideramos que devem ser levadas em conta para pensar no futuro da educação.

Palavras-chave: estudantes; pandemia; diversidade; educação superior; covid-19

Student perceptions, from their diversity, on the effects of the transition to online modality in the context of the COVID-19 pandemic.

Abstrac. The study analyzes some of the effects on students of the transition to the online modality in the context of the pandemic. It starts by problematizing the way in which the closing of schools, social isolation, and the set of restrictions to students' freedom, brought about profound changes in the forms of socialization and human interaction, as well as in the teaching-learning process, among which the radical change to online education stands out. Some effects of these transformations on students are analyzed through a questionnaire applied at the University of Guadalajara in two periods, July 2020 and January 2021. The analysis considers the differentiated impacts due to the diversity of students through variables such as gender, socioeconomic level, employment status, economic dependents, disabilities, belonging to an indigenous people and marital status. Among the findings we found that certain students suffer more than others from the effects of the phenomenon, including women and students with disabilities. But we also found that certain students with work and family responsibilities suffer to a lesser extent some of the effects. Differences that we believe should be considered when thinking about the future of education.

Keywords: students; pandemic; diversity; higher education; covid-19 


\section{Introducción}

El fenómeno de la pandemia ha trastocado el orden social en sus múltiples dimensiones económicas, políticas, pedagógicas y organizacionales, por citar algunas. El 11 de marzo de 2020, día en que la Organización Mundial de la Salud OMS, al considerar que el coronavirus COVID-19 había llegado a un alto nivel de propagación lo caracterizó como una pandemia, se ha convertido en un parteaguas sociohistórico que generó diversas crisis y ha provocado un estado de incertidumbre en muchos aspectos. El microcosmos que representa el sistema escolar, de alguna manera producto y reflejo del orden social, ha sido de igual manera transformado. Nunca antes se había visto un cierre de escuelas a nivel mundial de tal magnitud como el que se generó como medida de prevención por la pandemia. Se trata de un fenómeno sin precedentes, que sin duda dejará huella en los sistemas de educación superior de nuestros países.

A más de un año de suspensión de las clases presenciales es importante analizar la manera en que este hecho ha afectado a los estudiantes, quienes, al igual que profesores y demás actores de la educación superior, se vieron en la necesidad de atender y adaptarse a los nuevos requerimientos que la situación y el sistema escolar les demandaba. Para hacer este análisis consideramos necesario concebir al estudiante como sujeto complejo (Castellanos et al., 2015). Un sujeto que debe ser abordado desde su diversidad. Diversidad que era compleja desde antes de la pandemia, determinada por una mezcla de factores históricos, sociales, culturales, económicos, entre otros. Esta complejidad estructural se traduce en profundas desigualdades, en la que ciertos sectores de la población cuentan con mayores capitales, económicos, culturales y sociales que otros, y en las que ciertas condiciones particulares, como el género, la etnia o alguna discapacidad, se convierten en factores de vulnerabilidad que en muchos casos desembocan en estados de exclusión social o educativa (Castellanos et al., 2019). Este contexto heterogéneo y desigual se complejizó con la llegada de la pandemia ocasionada por el COVID-19. Los retos que representó para toda la población fueron sin duda más difíciles para los sectores poblacionales que no tenían las condiciones para adaptarse al cambio.

Seguramente el tiempo nos permitirá comprender cada vez mejor los efectos e implicaciones que ha tenido este fenómeno en la sociedad, sin embargo, la necesidad de emprender acciones e implementar políticas, programas y estrategias no puede esperar. Como toda crisis, la pandemia demanda a los actores de todos los niveles, gobernantes, directivos, empresarios, y a los mismos sujetos en su vida familiar y privada, la toma de decisiones. Decisiones que deberán tomarse en un contexto de incertidumbre, de manera rápida y expedita para enfrentar los retos que el fenómeno genera. En este contexto los estudios empíricos tienen gran relevancia por su potencial para ir perfilando ciertas interpretaciones sobre los efectos e impactos de este inusitado fenómeno, y a partir de ello estar en posibilidades de trazar con mayores elementos posibles rutas de acción. Este artículo se desprende de un proyecto que tiene por objetivo conocer la experiencia de los estudiantes de la Universidad de Guadalajara en el periodo de la pandemia. Para el presente texto se retoman, en particular, algunas variables relacionadas con los efectos que ha tenido la implementación de clases en línea en los estudiantes en este contexto, así como variables que dan cuenta de su 
diversidad, con el objetivo de analizar la manera diferenciada en que tales efectos se presentan atendiendo a dicha diversidad. Para ello, iniciaremos con un acercamiento a algunos elementos que marcaron el nuevo contexto de la educación que tienen que ver con el cierre de escuelas, el aislamiento social y el rol que se otorgó a las tecnologías de la información y la comunicación (TIC) como alternativa para hacer frente a la problemática.

\section{Cierre de escuelas y aislamiento social}

La instituciones de educación superior, en la misma tendencia que otros niveles educativos, se vieron en la necesidad de implementar acciones para reducir los contagios, lo que las llevó a una reorganización de actividades administrativas, académicas y prácticas educativas. El más evidente y conocido de los cambios ha sido la transición de un esquema predominante presencial a un esquema de clases en línea. La necesidad de aislamiento, por el alto riesgo de contagio, las llevó a tomar medidas de prevención, cancelando las clases presenciales aun cuando no se contaba con un plan de implementación de las clases en línea, ni con la normatividad necesaria para regular derechos y obligaciones de docentes y estudiantes, sistemas de control y vigilancia de los procesos educativos y sobre todo, se iniciaron las actividades en línea con una planta académica sin experiencia en esta modalidad y sin un plan de formación docente en este sentido.

Según datos de la UNESCO, para finales del mes de marzo del 2020, $1,457,223,744$ estudiantes a nivel global, que corresponden al $83.2 \%$ del total de alumnos matriculados, fueron afectados por el cierre de escuelas como respuesta a la pandemia. Aunque un año después, en marzo 2021, esta cifra se redujo a 163,921,494 estudiantes afectados, correspondiente al $9.4 \%$ del total de alumnos matriculados (UNESCO, 2021), es evidente la magnitud del impacto que se tuvo a nivel global.

El objetivo del cierre de las escuelas fue contribuir al aislamiento social. Aislamiento que trastoca la naturaleza misma de los estudiantes, dado que el ser humano es un ser social por naturaleza que se forma crece y desarrolla en interacción con otros seres humanos. La socialización no es solamente un proceso recreativo y lúdico, es la base de la construcción del orden social, espacio de construcción, intercambio y movilización del conocimiento, marco en el cual se crea y recrea la cultura. En la socialización aprendemos a vivir en el mundo, aprendemos valores, conocimientos y actitudes que guían nuestro comportamiento y nuestras decisiones. La interacción social tiene implicaciones no solo en los aspectos económicos, políticos y sociales del mundo moderno, sino que también influye de manera importante en nuestra subjetividad, en la construcción de identidades y en la propia salud mental.

La pandemia transformó totalmente la relación educativa impulsando nuevas formas de comunicación, en las que las sesiones remotas, la comunicación asincrónica, y en general el uso de diversas herramientas tecnológicas median los procesos de interacción entre profesores y estudiantes. El espacio abierto que los estudiantes encontraban en la escuela, que les permitía la interacción social en las aulas, laboratorios, espacios de recreación, se cambió por los espacios cerrados, que cada estudiante tuvo que adaptar en sus casas. La interacción cara a cara se transformó en interacciones mediadas por los dispositivos electrónicos a través de chats, video- 
conferencias y demás herramientas de comunicación. La tendencia creciente del uso de dispositivos electrónicos para la interacción social que se venía dando antes de la pandemia tuvo un crecimiento exponencial a consecuencia de las acciones de aislamiento social. La diferencia es que antes de la pandemia la socialización mediada por tecnologías era una opción y posteriormente durante la pandemia en muchos de los casos se convirtió en la "única" opción. Este hecho, como muchos otros que se generaron en este periodo, tiene importantes implicaciones por la manera en que se reduce y en ocasiones se elimina, la capacidad de elección de los sujetos. Esta reducción en las posibilidades de elección se presentó acompañada de una serie de restricciones hacia los mismos sujetos para transitar libremente, para ingresar a edificios y lugares públicos, para organizar o participar en reuniones y eventos masivos, para viajar - muchos países cerraron sus fronteras e implementaros restricciones en los puntos de ingreso y egreso-, todo ello generó la pérdida de uno de los valores más valorados y preciados del ser humano: la libertad.

Nos enfrentamos a nuevas restricciones que se suman a la ya compleja sociedad cada vez más regulada y vigilada que Focault definió como "sociedad disciplinaria" (Foucault, 2002), en la que surge un nuevo imperativo: el encierro. Si bien el encierro no se origina como un castigo, sino como una necesidad y una responsabilidad, se convierte en objeto de vigilancia, y en algunos casos de castigo cuando se observa su incumplimiento. Cuando hablamos de castigo, nos referimos no solo a las sanciones jurídicas, al "castigo-cuerpo" o "castigo disciplinario", en sentido foucaltiano, sino a todo el entramado de sanciones morales y sociales que se construyen socioculturalmente frente a un fenómeno tan complejo como éste.

Aeste estado complejo de restricciones que enfrentaron los estudiantes, quienes, como todos, se vieron en la necesidad de aislarse, hay que añadir que el contexto de alto riesgo generó, entre otras cosas, un estado de miedo e incertidumbre. El miedo se convirtió en uno de los principales detonantes, no solo para que las personas asumieran la necesidad de aislamiento, sino también para el establecimiento de normas y sanciones. Principalmente el miedo al contagio, tanto personal como de los familiares y amigos; pero, además, el miedo de los gobernantes a tomar decisiones erróneas que pongan en peligro la salud de la población, cuando es uno de los principales responsables de su seguridad; el miedo a las repercusiones económicas y sociales de paralizar algunos sectores de la economía; así como el miedo a un futuro incierto.

Aislamiento, restricciones, pérdida de la libertad, miedo e incertidumbre son algunas de las cuestiones que tuvieron que enfrentar los estudiantes, y en este contexto continuar con su proceso de enseñanza aprendizaje. Surge la necesidad de comprender los impactos que todo ello generó en ellos, en particular en sus procesos de formación. En este contexto es importante considerar que no todos tienen las mismas posibilidades de soportar y superar las problemáticas comunes, sino que existe una gran heterogeneidad y diversidad de estudiantes, con diferentes condiciones y marcadas desigualdades, lo que provoca que las dificultades de adaptación sean mayores para ciertos sectores que poseen caracteríticas particulares que los vuelven más vulnerables. 


\section{La apuesta por las TIC y sus desafíos ante la diversidad estudiantil}

La pandemia trajo consigo una gran cantidad de retos, entre los que se encuentran hacer frente a una histórica desigualdad, en la que existen grupos vulnerables relacionados con condiciones de pobreza, pertenencia étnica, genero, discapacidad, entre otros. Condiciones de desigualdad que a raíz de la pandemia se hicieron más radicales y marcadas. El reto de la educación de buscar los mecanismos para hacer frente a dichas desigualdades es ahora mayor. La expectativa de generar una relación virtuosa entre la educación, el crecimiento y la disminución de las desigualdades, en la que se espera que por un lado la educación pueda acelerar el crecimiento y disminuir la desigualdad; y por el otro, una mayor equidad pueda favorecer el crecimiento, enfrenta una realidad compleja en la que en ocasiones sucede lo contrario y "puede ocurrir que las características de la educación contribuyan a la desigualdad y frenen el crecimiento" (Beristain, 2005, p. 39). Este es uno de los riesgos que trae consigo la educación mediada por tecnologías. Todas las ventajas que ofrecen, como son el acceso remoto y la apertura a las inmensas cantidades de información que ofrece internet, pueden ser elementos tanto para la inclusión como para la exclusión social. La diferencia radica en si se cuenta o no con las condiciones para aprovechar todas esas ventajas. A pesar de los riesgos que conlleva la elección por las TIC se presentó como la mejor o única alternativa a seguir y en este contexto complejo y cambiante se convirtieron en el aliado estratégico para hacer frente a la problemática.

Si bien aparentemente había un consenso en el potencial de las TIC como alternativa para no suspender las clases, aún quedaban muchas cuestiones por resolver. Las instituciones y sus profesores se enfrentaron con una enorme cantidad de opciones y disyunciones relacionadas con el uso de herramientas sincrónicas o asincrónicas, plataformas de cursos o envío de actividades por correo electrónico, aplicaciones de mensajería, entre otros. En un momento de mayor avance algunos profesores que buscaron nuevas herramientas se veían también en la disyuntiva de producir o buscar en la red aplicaciones, productos y materiales educativos. En la mayoría de los casos, sea cual fuere la elección tomada, eran necesarios nuevos aprendizajes, por lo que la demanda de formación docente aumentó.

Los estudiantes enfrentaron el reto de adaptarse a las dinámicas, a los diferentes estilos docentes que poseen diversos grados de dominio de las herramientas tecnológicas, y muchos de ellos con grandes dificultades para implementarlas. Todo ello trajo consigo una diversidad de formas de interacción entre profesores y estudiantes. Algunos profesores iniciaron organizando actividades para trabajo en casa que se transmitían por los más diversos medios como correo electrónico o aplicaciones de mensajería. Los más avanzados diseñaron cursos en plataformas de cursos en línea y diversos recursos educativos.

Los estudiantes se enfrentaron a una amplia diversidad de estilos y formas de impartir las clases, muchos de ellos con grandes carencias, situación que se complejizaba con los problemas y dificultades de conectividad, de acceso a dispositivos para conectarse, entre otros. Tanto profesores como alumnos se vieron en la necesidad de hacer frente a éstas y a otras problemáticas, algunos incluso a su analfabetismo tecnológico. 
Es así que las TIC surgen como alternativa para dar continuidad con el proceso educativo, sin embargo, llegaron también acompañadas de problemáticas complejas. Los problemas tecnológicos se suman a los problemas derivados del aislamiento social, los efectos económicos, las desigualdades sociales, entre otros. A partir de esta problemática, surge la pregunta que guía el presente trabajo: ¿cuáles son los efectos de la transición de las clases presenciales a clases en línea generados en el periodo de la pandemia en los estudiantes desde su diversidad?

\section{Metodología}

Para dar respuesta a la interrogante planteada se recuperan las percepciones y opiniones de estudiantes de la Universidad de Guadalajara a través de un cuestionario. El cuestionario se aplicó en dos periodos de tiempo, en el mes de julio de 2020 y en el mes de enero del 2021. El primer periodo corresponde al cierre del semestre 2020A de la universidad, que comprende el periodo enero-junio y el segundo corresponde al semestre 2020B que comprende el periodo septiembre-diciembre.

El instrumento se aplicó de manera digital a través del Sistema Integral de Información y Administración Universitaria SIIAU, plataforma oficial de la Universidad de Guadalajara, en la que se concentran diversas bases de datos institucionales. En el calendario 2020A se obtuvieron 15,108 cuestionarios y en el calendario $2020 \mathrm{~B}$ se lograron 89,033, dando un total de 104,101 cuestionarios que representan ambos calendarios del 2020. En el presente texto se discuten seis variables que tienen que ver con los efectos que tuvo la pandemia en los estudiantes.

La forma en que fue presentada a los estudiantes en el cuestionario fue de la siguiente manera: “En general, considero que la modalidad en línea que se implementó en el contexto de la pandemia:

1. Afectó mi avance académico y mi proceso de formación

2. Me resultó más difícil aprender

3. Me generó mayor estrés

4. Me generó nuevos gastos (internet, equipo)

5. Me demanda más tiempo que la modalidad presencial

6. Me demanda un mayor esfuerzo

Estas variables fueron sometidas a análisis como variables dependientes. La medición se llevó a cabo a través de una escala likert expresada en la forma de "total acuerdo" hasta "total descuerdo". Se consideraron puntuaciones negativas para los dos niveles de desacuerdo y positivas para los dos niveles de acuerdo, dejando un punto intermedio para dar oportunidad a los estudiantes a que contesten "ni acuerdo ni en desacuerdo". La escala quedó de la siguiente manera:
-2. Completamente en desacuerdo
-1. En desacuerdo
0 . Ni acuerdo ni en desacuerdo
1. De acuerdo
2. Completamente de acuerdo

Estas variables fueron cruzadas con las siguientes variables que jugaron el rol de variables independientes y que se utilizan con el objetivo de dar cuenta de la diversidad de los estudiantes: 
1. Género

2. Condiciones laborales

3. Estado civil

4. Dependientes económicos

5. Pertenencia a pueblo indígena

6. Discapacidad

7. Nivel socioeconómico

El análisis se llevó a cabo en el software SPSS, en un primer momento se utilizaron estadísticos descriptivos de frecuencias y porcentajes de cada una de las variables. Posteriormente se procedió a "comparar medias" de las variables dependientes en su cruce con las independientes, para analizar la manera en que la diversidad de estudiantes experimentó los cambios derivados del periodo de pandemia. El análisis se complementó con la prueba Gamma y el Coeficiente de Contingencia para medir la significancia de la relación de variables ordinales y nominales respectivamente. Las tablas y gráficos se procesaron en excel.

La comparación de medias permite distinguir los grados "de acuerdo" o "total acuerdo" que se presentan y grafican con la escala de 0 a 2 positiva, o en su caso los grados de "desacuerdo" o "total desacuerdo" medidos con la escala de 0 a -2 (negativa). Para interpretar los resultados se toma en cuenta la distancia del promedio de las respuestas con relación al cero. Entre más se aleja del cero en sentido positivo es mayor el grado de acuerdo con la afirmación y entre más se aleje del cero en sentido negativo es mayor el grado de desacuerdo con la misma. Las posiciones cercanas a 0 se leen como posiciones neutras que no se identifican con ninguno de los dos extremos.

\section{Análisis de los resultados}

Iniciaremos con el análisis de las variables dependientes que describen algunas de las problemáticas que enfrentaron los estudiantes y que resultaron significativas en el análisis. La figura 1 representa la forma en que se distribuyeron las respuestas en las seis variables de interés entre el "totalmente en desacuerdo" y el "totalmente de acuerdo".

La distribución muestra la manera en que la variable "me generó mayor estrés" presenta la más marcada relación ascendente, en la que las respuestas positivas de "totalmente de acuerdo" (40.3\%) y "de acuerdo" (29.7\%) son notoriamente mayores que las negativas. Esta relación ascendente se muestra también en las dos primeras variables, y en menor medida en las dos últimas. Solamente la variable "me genero nuevos gastos" arroja una distribución en curva a diferencia de las anteriores.

Si bien esta representación nos aporta interesantes detalles sobre la distribución de las respuestas haremos uso de la herramienta "comparación de medias" para sintetizar la relación positiva o negativa de la variable y permitir su comparación (ver figura 2). 
Figura 1. Representación gráfica de la distribución de las respuestas por porcentaje de las seis variables dependientes

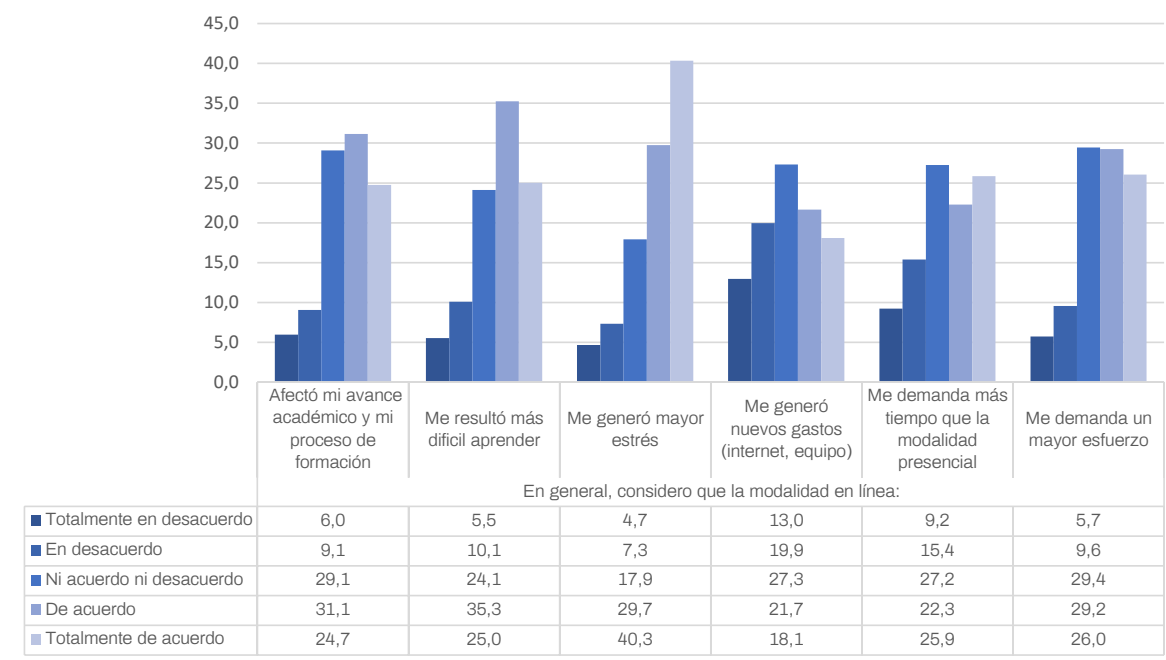

Fuente: elaboración propia.

Figura 2. Representación gráfica las seis variables dependientes mediante la comparación de medias

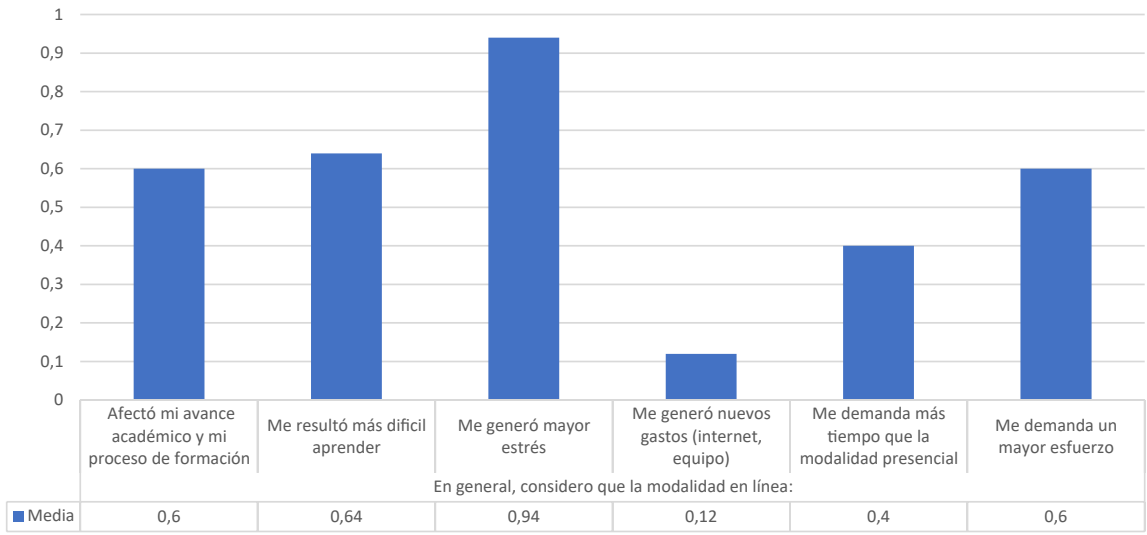

Fuente: elaboración propia.

La figura muestra que las seis variables tienen una media por arriba de cero. La más alejada es la de "me generó mayor estrés" que podemos ver desglosada en la figura 1 en la que las respuestas positivas son notoriamente mayores que las negativas dibujando una línea ascendente. Por el contrario, la variable "me generó nuevos gastos" muestra un mayor equilibrio entre respuestas positivas y negativas que se refleja en una curva (figura 1) y se traduce en una media mucho más cercana a cero (figura 2). 
La distribución por medias nos permite ver el grado de importancia de cada variable y nos facilita su comparación en el cruce con otras variables.

\subsection{Diferencias por género}

La encuesta aplicada logró 104,141 respuestas, de la cuales 58,160 que corresponden al 55.8\%, son mujeres y 45,981 (44.2\%) son hombres.

Tabla 1. Frecuencias y porcentaje de respuestas por género

\begin{tabular}{lcc}
\hline & Frecuencia & Porcentaje \\
\hline Hombre & 45981 & 44.2 \\
Mujer & 58160 & 55.8 \\
Total & 104141 & 100 \\
\hline
\end{tabular}

Fuente: elaboración propia.

Tanto la prueba de Coeficiente de contingencia como la prueba Gamma arrojan resultados significativos en todos y cada uno de los cruces con las variables dependientes analizadas, lo que hace evidente que las variables están significativamente relacionadas.

Tabla 2. Nivel de significancia del cruce de la variable "género" con cada una de las seis variables dependientes

\begin{tabular}{|c|c|c|c|c|c|c|c|}
\hline & & $\begin{array}{l}\text { Afec- } \\
\text { tó mi } \\
\text { avance } \\
\text { académi- } \\
\text { co y mi } \\
\text { proceso } \\
\text { de for- } \\
\text { mación }\end{array}$ & $\begin{array}{l}\text { Me resul- } \\
\text { tó más } \\
\text { difícil } \\
\text { aprender }\end{array}$ & $\begin{array}{c}\text { Me gene- } \\
\text { ró mayor } \\
\text { estrés }\end{array}$ & $\begin{array}{c}\text { Me } \\
\text { generó } \\
\text { nuevos } \\
\text { gastos } \\
\text { (internet, } \\
\text { equipo) }\end{array}$ & $\begin{array}{c}\text { Me de- } \\
\text { manda } \\
\text { más } \\
\text { tiempo } \\
\text { que la } \\
\text { modali- } \\
\text { dad pre- } \\
\text { sencial }\end{array}$ & $\begin{array}{c}\text { Me de- } \\
\text { manda } \\
\text { un mayor } \\
\text { esfuerzo }\end{array}$ \\
\hline \multirow{2}{*}{$\begin{array}{l}\text { Significación } \\
\text { aproximada }\end{array}$} & $\begin{array}{l}\text { Coeficiente de } \\
\text { contingencia }\end{array}$ & 0.000 & 0.000 & 0.000 & 0.000 & 0.000 & 0.000 \\
\hline & Gamma & 0.000 & 0.000 & 0.000 & 0.000 & 0.000 & 0.000 \\
\hline
\end{tabular}

Fuente: elaboración propia.

Los resultados hacen visibles las diferencias de género y muestran la manera en que para las mujeres los efectos de la pandemia son mayores que para los hombres.

Si comparamos las medias, con excepción de las variables relacionadas con la percepción de las afectaciones que tuvo la pandemia en el avance académico y en el proceso de formación, y la variable de "me generó nuevos gastos", en todas las demás variables es notoriamente mayor el efecto promedio en el género femenino.

Las mujeres manifiestan que les "resultó más difícil aprender" en el nuevo contexto, que se refleja en una media de 0.67 en comparación del 0.60 de los hombres. Pero las variables donde las diferencias son mayores tienen que ver con el estrés, la demanda de tiempo y de esfuerzo. 
Figura 3. Representación gráfica del cruce de la variable "género" con las seis variables dependientes mediante la comparación de medias

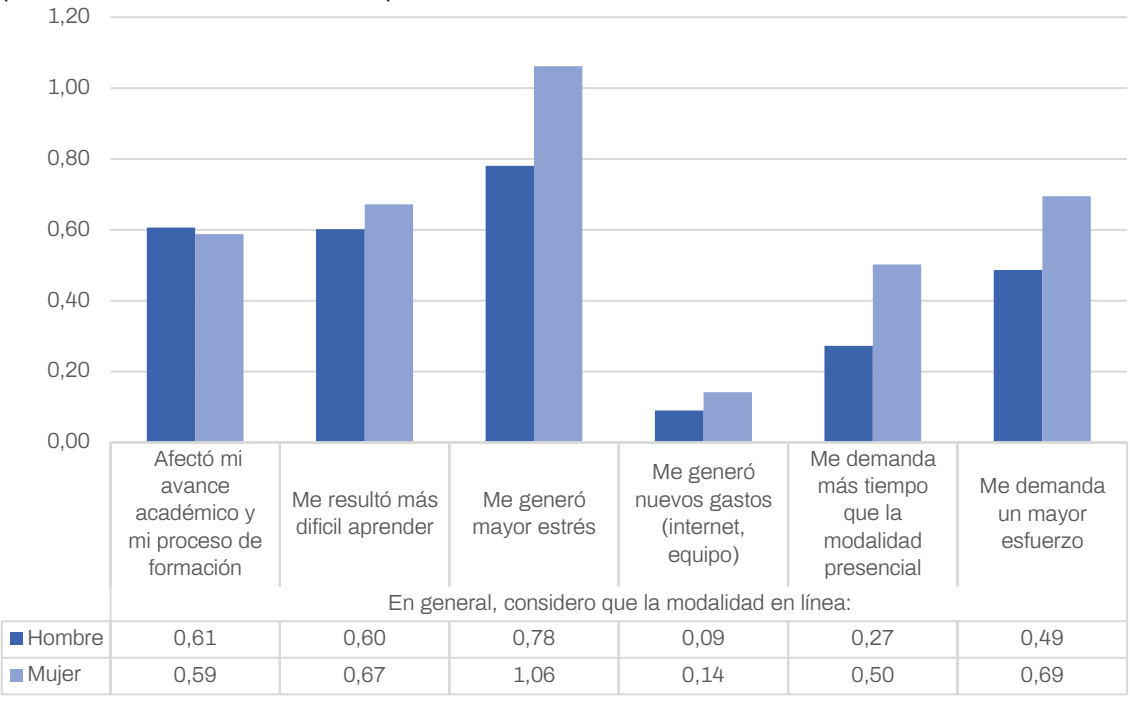

Fuente: elaboración propia.

La media en las respuestas de los hombres sobre la variable "me generó mayor estrés", si bien es alta al llegar a un 0.78, en las mujeres es mayor, ya que llegan a un 1.06, lo que es verdaderamente preocupante. La percepción de las mujeres sobre "me demanda más tiempo que la modalidad presencial" llega a 0.50, por lo que también supera a la de los hombres que arrojó una media de 0.27. Situación similar encontramos en la variable "me demanda un mayor esfuerzo" que en los hombres llegó a un 0.49 y en las mujeres a un 0.69 .

\subsection{Condiciones laborales}

En relación a las condiciones laborales de los estudiantes encontramos que más de la mitad de los estudiantes no trabajan (51.8\%), al menos en el año en que se aplicó la encuesta en el contexto de la pandemia. Los estudiantes que señalaron que trabajan lo hacen con distintas cargas horarias, un $10.2 \%$ de ellos trabaja menos de 10 horas a la semana; un $8.1 \%$ entre 10 y 20 horas; un $7.9 \%$ entre 20 y 30; un $9.8 \%$ entre 30 y 40 ; y por último un $12.3 \%$ trabaja más de 40 horas a la semana. Los rangos de carga horaria de los estudiantes que trabajan, en este sentido se encuentran relativamente equilibrados (tabla 3 ).

Dada la naturaleza ordinal de las variables en cuestión, nos interesan, en particular, los resultados de significancia de la prueba Gamma, los cuales señalan que tres variables tienen cruces significativos con la variable "situación laboral" y tres no lo tienen, si consideramos el nivel de significancia al 0.05 (tabla 4). 
Tabla 3. Frecuencias y porcentaje de respuestas por situación laboral

\begin{tabular}{lcc}
\hline & Frecuencia & Porcentaje \\
\hline No trabajo & 53894 & 51.8 \\
Sí, menos de 10 horas a la semana & 10608 & 10.2 \\
Sí, entre 10 y menos de 20 horas a la semana & 8444 & 8.1 \\
Sí, entre 20 y menos de 30 horas a la semana & 8182 & 7.9 \\
Sí, entre 30 y menos de 40 horas a la semana & 10186 & 9.8 \\
Más de 40 horas a la semana & 12827 & 12.3 \\
Total & 104141 & 100 \\
\hline
\end{tabular}

Fuente: elaboración propia.

Tabla 4. Nivel de significancia del cruce de la variable "situación laboral" con cada una de las seis variables dependientes

\begin{tabular}{|c|c|c|c|c|c|c|c|}
\hline & & $\begin{array}{c}\text { Afec- } \\
\text { tó mi } \\
\text { avance } \\
\text { académi- } \\
\text { co y mi } \\
\text { proceso } \\
\text { de for- } \\
\text { mación }\end{array}$ & $\begin{array}{l}\text { Me resul- } \\
\text { tó más } \\
\text { difícil } \\
\text { aprender }\end{array}$ & $\begin{array}{c}\text { Me } \\
\text { generó } \\
\text { mayor } \\
\text { estrés }\end{array}$ & $\begin{array}{c}\text { Me } \\
\text { generó } \\
\text { nuevos } \\
\text { gastos } \\
\text { (internet, } \\
\text { equipo) }\end{array}$ & $\begin{array}{c}\text { Me de- } \\
\text { manda } \\
\text { más } \\
\text { tiempo } \\
\text { que la } \\
\text { modali- } \\
\text { dad pre- } \\
\text { sencial }\end{array}$ & $\begin{array}{c}\text { Me de- } \\
\text { manda } \\
\text { un mayor } \\
\text { esfuerzo }\end{array}$ \\
\hline \multirow{2}{*}{$\begin{array}{l}\text { Significación } \\
\text { aproximada }\end{array}$} & $\begin{array}{l}\text { Coeficiente de } \\
\text { contingencia }\end{array}$ & 0.000 & 0.000 & 0.000 & 0.000 & 0.000 & 0.000 \\
\hline & Gamma & 0.640 & 0.093 & 0.000 & 0.000 & 0.000 & 0.090 \\
\hline
\end{tabular}

Fuente: elaboración propia.

Las variables no significativas son: "afectó mi avance académico y mi proceso de formación", "me resultó más difícil aprender" y "me demanda un mayor esfuerzo". Si visualizamos el gráfico de las medias, en ninguna de las tres se presenta una relación ascendente o descendente que muestre una relación entre ellas. Por el contrario, los tres cruces que arrojan una relación significativa hacen evidente esta relación cuando comparamos las medias.

Por lo que respecta al estrés la relación es negativa, en la media en que aumenta la carga de trabajo disminuye el estrés. Esto es, hay una percepción menos negativa de los efectos de estrés en los estudiantes que tienen mayor carga horaria laboral.

La variable "estrés" se comporta de manera semejante que la variable "me demanda más tiempo que la modalidad presencial". A mayor carga laboral es menor la percepción de afectación por el cambio de modalidad. En otras palabras, parece haber una menor afectación en los estudiantes que tienen mayor carga laboral por la nueva modalidad, la cual les representa menor estrés y menor demanda de tiempo a diferencia de los estudiantes que no trabajan, o trabajan menos horas, quienes, por el contrario, perciben una mayor demanda de tiempo y mayor estrés en el periodo de pandemia. 
Figura 4. Representación gráfica del cruce de la variable "situación laboral" con las seis variables dependientes mediante la comparación de medias

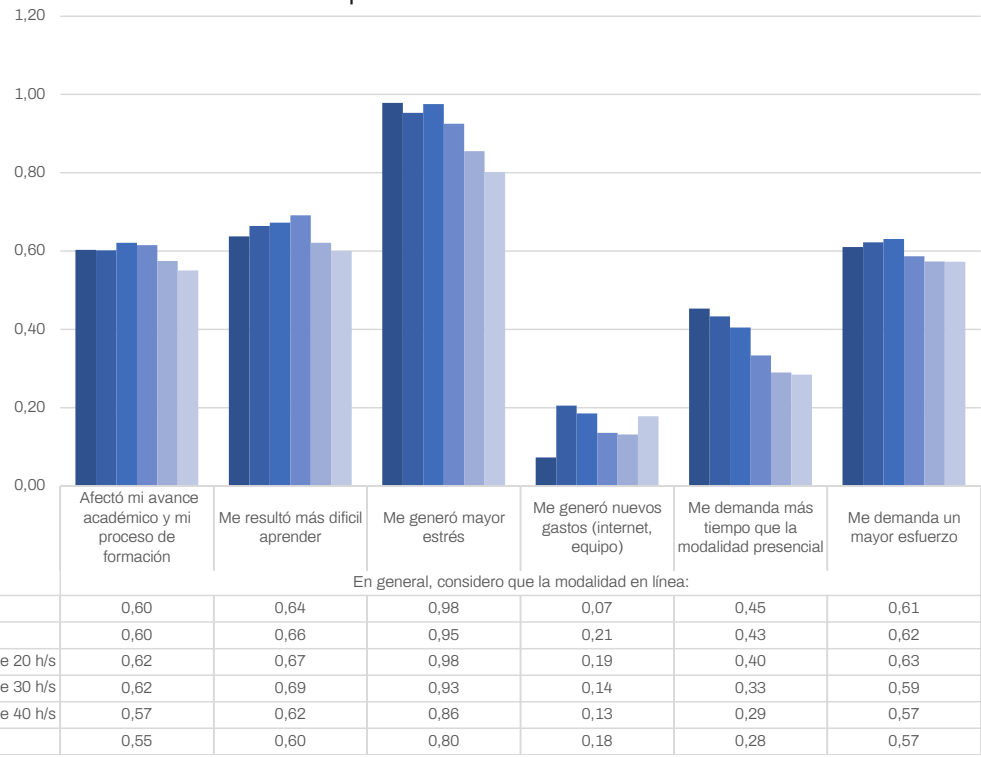

Fuente: elaboración propia.

\subsection{Estado civil}

En la muestra aplicada encontramos que el $92.6 \%$ de los estudiantes de la Universidad de Guadalajara son solteros. Esto representa a una contundente mayoría de la población estudiantil, a la cual le siguen el estado civil de casado con un $3.4 \%$ y el de unión libre con un 3.1\%.

Tabla 5. Frecuencias y porcentaje de respuestas por estado civil

\begin{tabular}{lrc}
\hline & Frecuencia & Porcentaje \\
\hline Soltero & 96405 & 92.6 \\
Casado & 3555 & 3.4 \\
Unión libre & 3198 & 3.1 \\
Viudo & 90 & 0.1 \\
Divorciado & 509 & 0.5 \\
Otro & 384 & 0.4 \\
Total & 104141 & 100 \\
\hline
\end{tabular}

Fuente: elaboración propia.

Los estudiantes viudos o divorciados, en conjunto, representan menos del $1 \%$ de la población. La categoría "otros" representa únicamente el 0.4 por ciento de las respuestas, la cual dada su mínima relevancia se decidió omitirla en los gráficos de comparación de medias. 
Tabla 6. Nivel de significancia del cruce de la variable "estado civil" con cada una de las seis variables dependientes

\begin{tabular}{|c|c|c|c|c|c|c|c|}
\hline & & $\begin{array}{l}\text { Afectó } \\
\text { mi avan- } \\
\text { ce aca- } \\
\text { démico } \\
\text { y mi } \\
\text { proceso } \\
\text { de for- } \\
\text { mación }\end{array}$ & $\begin{array}{c}\text { Me } \\
\text { resultó } \\
\text { más } \\
\text { difícil } \\
\text { aprender }\end{array}$ & $\begin{array}{c}\text { Me } \\
\text { generó } \\
\text { mayor } \\
\text { estrés }\end{array}$ & $\begin{array}{c}\text { Me } \\
\text { generó } \\
\text { nuevos } \\
\text { gastos } \\
\text { (internet, } \\
\text { equipo) }\end{array}$ & $\begin{array}{c}\text { Me } \\
\text { deman- } \\
\text { da más } \\
\text { tiempo } \\
\text { que la } \\
\text { moda- } \\
\text { lidad } \\
\text { presen- } \\
\text { cial }\end{array}$ & $\begin{array}{c}\text { Me } \\
\text { deman- } \\
\text { da un } \\
\text { mayor } \\
\text { esfuerzo }\end{array}$ \\
\hline \multirow{2}{*}{$\begin{array}{l}\text { Significación } \\
\text { aproximada }\end{array}$} & $\begin{array}{l}\text { Coeficiente de } \\
\text { contingencia }\end{array}$ & 0.000 & 0.000 & 0.000 & 0.000 & 0.000 & 0.000 \\
\hline & Gamma & 0.000 & 0.000 & 0.000 & 0.000 & 0.000 & 0.000 \\
\hline
\end{tabular}

Fuente: elaboración propia.

Las pruebas de significancia nos muestran que las variables están relacionadas, lo que se puede visualizar cuando comparamos las medias. En las 6 variables destacan en primer lugar los estudiantes solteros que manifiestan un mayor grado de afectación en el periodo de la pandemia.

En la variable "afectó mi avance académico y mi proceso de formación", manifiesta un grado de acuerdo de 0.63 notoriamente lejano a los demás estudiantes no solteros. El más cercano es el grupo de los estudiantes en "unión libre" con una media de 0.37. Muy próximos al cero se encuentran los casados (0.05) y los divorciados (0.09) e incluso por debajo del cero se manifestaron los estudiantes viudos que llegaron a -0.17 .

Figura 5. Representación gráfica del cruce de la variable "estado civil" con las seis variables dependientes mediante la comparación de medias

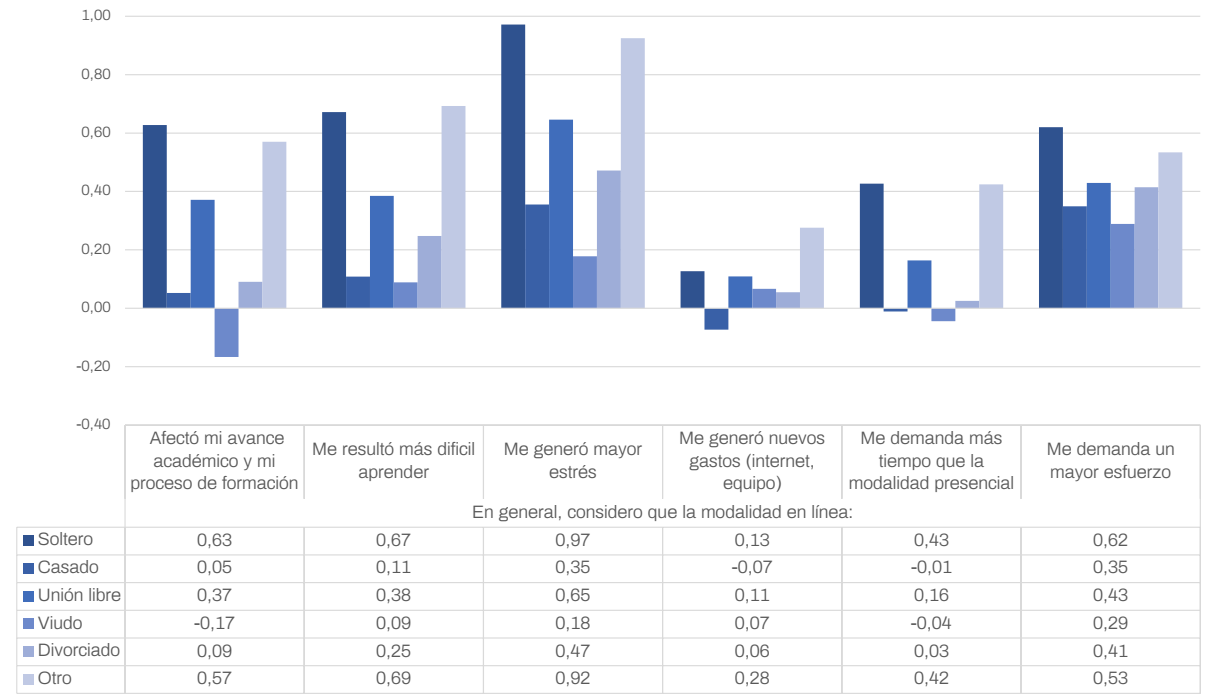

Fuente: elaboración propia. 
Los comportamientos siguen un patrón parecido con las otras variables, la diferencia de los solteros en relación al resto de los estudiantes es evidentemente amplia en todas las variables, con excepción de la variable "me generó nuevos gastos" en la que la diferencia es menor.

\subsection{Dependientes económicos}

Cerca de una tercera parte de los estudiantes tienen uno o dos dependientes económicos (31\%), un 3.3\% tiene tres y un $2.7 \%$ tiene tres o más.

Tabla 7. Frecuencias y porcentaje de respuestas por número de dependientes económicos

\begin{tabular}{lcc}
\hline & Frecuencia & Porcentaje \\
\hline Ninguno & 65508 & 62.9 \\
1 & 19420 & 18.6 \\
2 & 12902 & 12.4 \\
3 & 3466 & 3.3 \\
4 & 1578 & 1.5 \\
5 & 801 & 0.8 \\
6 o más & 466 & 0.4 \\
Total & 104141 & 100 \\
\hline Fuente: elaboración propia. &
\end{tabular}

Fuente: elaboración propia.

Las pruebas estadísticas arrojan resultados significativos, por lo que pasaremos a analizar el sentido positivo o negativos de las relaciones.

Tabla 8. Nivel de significancia del cruce de la variable "dependientes económicos" con cada una de las seis variables dependientes

\begin{tabular}{|c|c|c|c|c|c|c|c|}
\hline & & $\begin{array}{c}\text { Afec- } \\
\text { tó mi } \\
\text { avance } \\
\text { acadé- } \\
\text { mico y } \\
\text { mi pro- } \\
\text { ceso de } \\
\text { forma- } \\
\text { ción }\end{array}$ & $\begin{array}{c}\text { Me } \\
\text { resultó } \\
\text { más } \\
\text { difícil } \\
\text { apren- } \\
\text { der }\end{array}$ & $\begin{array}{c}\text { Me } \\
\text { generó } \\
\text { mayor } \\
\text { estrés }\end{array}$ & $\begin{array}{c}\text { Me } \\
\text { generó } \\
\text { nuevos } \\
\text { gastos } \\
\text { (inter- } \\
\text { net, } \\
\text { equipo) }\end{array}$ & $\begin{array}{c}\text { Me } \\
\text { deman- } \\
\text { da más } \\
\text { tiempo } \\
\text { que la } \\
\text { moda- } \\
\text { lidad } \\
\text { presen- } \\
\text { cial }\end{array}$ & $\begin{array}{c}\text { Me } \\
\text { deman- } \\
\text { da un } \\
\text { mayor } \\
\text { esfuer- } \\
\text { zo }\end{array}$ \\
\hline \multirow{2}{*}{$\begin{array}{l}\text { Significación } \\
\text { aproximada }\end{array}$} & $\begin{array}{l}\text { Coeficiente de } \\
\text { contingencia }\end{array}$ & 0.000 & 0.000 & 0.000 & 0.000 & 0.000 & 0.000 \\
\hline & Gamma & 0.000 & 0.000 & 0.000 & 0.000 & 0.001 & 0.003 \\
\hline
\end{tabular}

Fuente: elaboración propia.

En las tres primeras, y en menor medida en las dos últimas, la relación es negativa. En la medida que aumentan los dependientes económicos disminuye el grado de afectación de la variable dependiente. 
En el caso de los estudiantes que no tienen dependientes económicos en la variable "afectó mi avance académico y mi proceso de formación" la media llega a 0.63 y en la segunda "me resultó á difícil aprender", a 0.67, estadístico que se va reduciendo en relación al aumento de dependientes.

Figura 6. Representación gráfica del cruce de la variable "dependientes económicos" con las seis variables dependientes mediante la comparación de medias

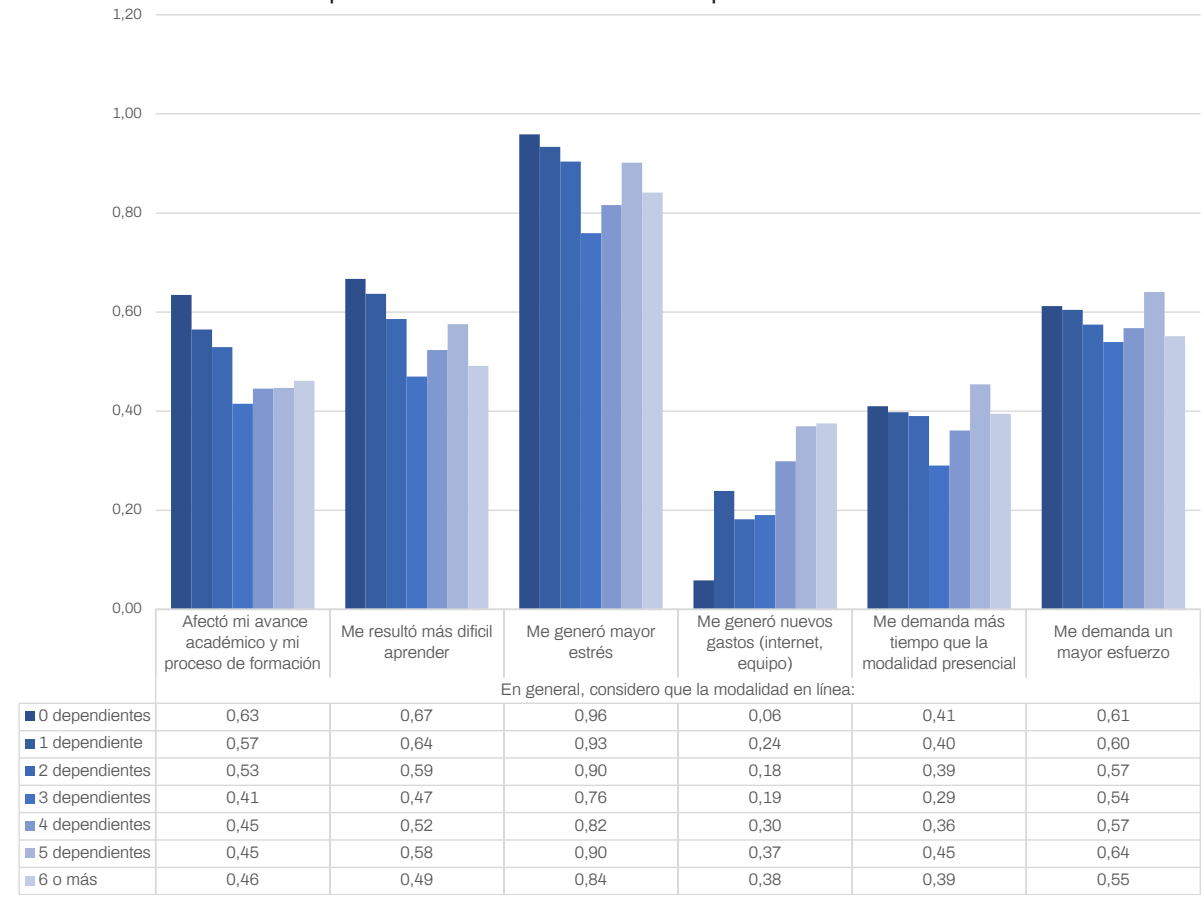

Fuente: elaboración propia.

El grado de estrés arroja un resultado semejante, los estudiantes sin dependientes económicos manifiestan una afectación mayor del estrés que los demás. Si bien la diferencia es menor, las últimas dos variables nos indican que entre menos dependientes económicos es mayor la demanda de tiempo y esfuerzo que, desde la perspectiva de los estudiantes, trajo consigo el cambio de modalidad.

En la variable "me generó nuevos gastos", la relación es positiva, a medida que aumenta el número de dependientes, aumenta el grado de acuerdo con la afirmación. Es decir, hay una percepción mayor de nuevos gastos entre más dependientes económicos tienen.

\subsection{Pertenencia a pueblo indígena}

En los cuestionarios obtenidos, 968 estudiantes manifestaron pertenecer a un pueblo indígena, que representa menos del $1 \%$ del total. 
Tabla 9. Frecuencias y porcentaje de respuestas de los estudiantes que pertenecen a una comunidad indígena

\begin{tabular}{lcc}
\hline & Frecuencia & Porcentaje \\
\hline No & 103173 & 99.1 \\
Sí & 968 & 0.9 \\
Total & 104141 & 100 \\
\hline
\end{tabular}

Fuente: elaboración propia.

Las variables "afectó mi avance académico", "me resultó más difícil aprender" y "me generó nuevos gastos" resultaron significativas con el coeficiente de contingencia al 0.05

Tabla 10. Nivel de significancia del cruce de la variable "pertenencia a pueblo indígena" con cada una de las seis variables dependientes

\begin{tabular}{|c|c|c|c|c|c|c|c|}
\hline & & $\begin{array}{c}\text { Afectó } \\
\text { mi avan- } \\
\text { ce aca- } \\
\text { démico } \\
\text { y mi } \\
\text { proceso } \\
\text { de for- } \\
\text { mación }\end{array}$ & $\begin{array}{c}\text { Me } \\
\text { resultó } \\
\text { más } \\
\text { difícil } \\
\text { apren- } \\
\text { der }\end{array}$ & $\begin{array}{c}\text { Me } \\
\text { generó } \\
\text { mayor } \\
\text { estrés }\end{array}$ & $\begin{array}{c}\text { Me } \\
\text { generó } \\
\text { nuevos } \\
\text { gastos } \\
\text { (internet, } \\
\text { equipo) }\end{array}$ & $\begin{array}{c}\text { Me } \\
\text { deman- } \\
\text { da más } \\
\text { tiempo } \\
\text { que la } \\
\text { moda- } \\
\text { lidad } \\
\text { presen- } \\
\text { cial }\end{array}$ & $\begin{array}{c}\text { Me } \\
\text { deman- } \\
\text { da un } \\
\text { mayor } \\
\text { esfuerzo }\end{array}$ \\
\hline \multirow{2}{*}{$\begin{array}{l}\text { Significación } \\
\text { aproximada }\end{array}$} & $\begin{array}{l}\text { Coeficiente de } \\
\text { contingencia }\end{array}$ & 0.048 & 0.011 & 0.111 & 0.000 & 0.531 & 0.247 \\
\hline & Gamma & 0.253 & 0.023 & 0.055 & 0.000 & 0.378 & 0.202 \\
\hline
\end{tabular}

Fuente: elaboración propia.

Figura 7. Representación gráfica del cruce de la variable "pertenencia a pueblo indígena" con las seis variables dependientes mediante la comparación de medias

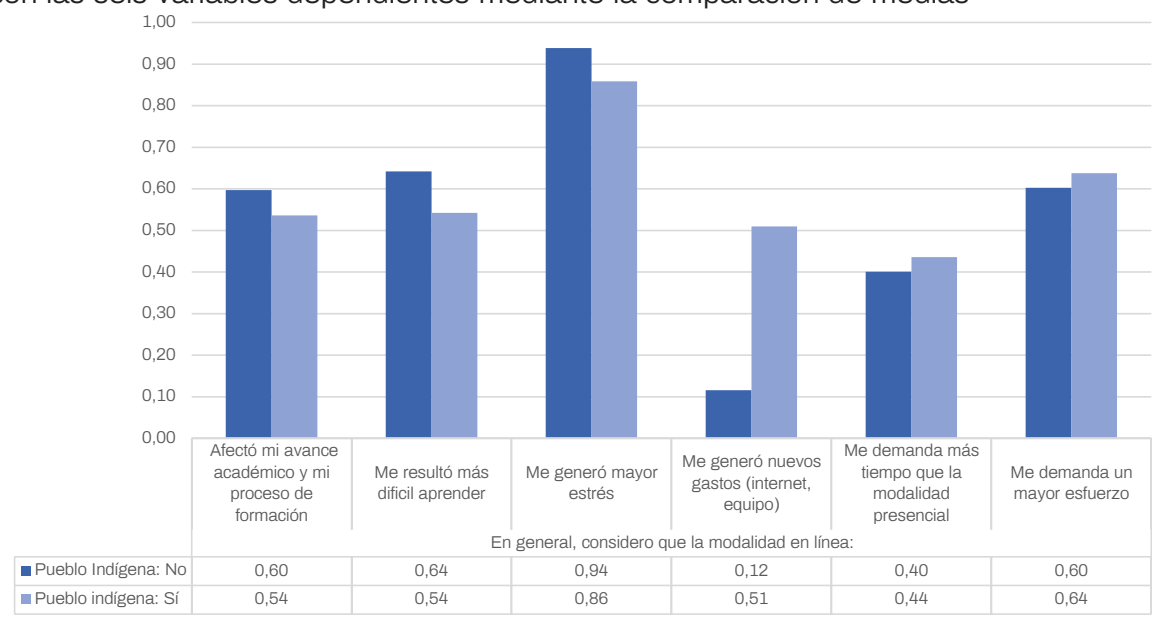

Fuente: elaboración propia. 
La relación en el cruce con las primeras tres variables es negativa y en el cruce con las tres últimas es positiva. Esto es la pertenencia a un pueblo indígena arroja una media menor cuando se refiere a "afectó mi avance académico y mi proceso de formación", "me resultó más difícil aprender" y "me generó mayor estrés".

Contrario a los resultados esperados los estudiantes indígenas se ven afectados en menor medida que los estudiantes no indígenas en estas tres variables. La relación contraria la encontramos en "me demanda más tiempo" (0.44) y "me demanda un mayor esfuerzo" (0.64), en la que los estudiantes indígenas tienen una media 4 puntos mayor en la primera y 6 en la segunda, diferencias que resultan poco significativas estadísticamente.

Por otro lado, la variable "me generó nuevos gastos" muestra una de las más altas diferencias en relación con sus compañeros no indígenas al llegar a una media de 0.51 , esto es una diferencia de 39 centésimas. Lo anterior hace evidente que, si bien los estudiantes indígenas son sensibles a todas las afectaciones, la que marca la diferencia con relación a los estudiantes no indígenas es el factor económico.

\subsection{Estudiantes con discapacidad}

Del total de estudiantes que respondieron la encuesta 2,347 manifestaron tener alguna discapacidad, cifra que corresponde al $2.3 \%$ del total de cuestionarios.

Tabla 11. Frecuencias y porcentaje de respuestas de los estudiantes con discapacidad

\begin{tabular}{lcc} 
& Frecuencia & Porcentaje \\
\hline No & 101794 & 97.7 \\
Sí & 2347 & 2.3 \\
Total & 104141 & 100 \\
\hline
\end{tabular}

Fuente: elaboración propia.

Esta variable resultó significativa en sus cruces con cada una de las seis variables dependientes, es decir, existe una importante relación entre los efectos de las transformaciones en la modalidad de enseñanza derivados de la pandemia con el hecho de tener, o no, una discapacidad.

Tabla 12. Nivel de significancia del cruce de la variable "estudiantes con discapacidad" con cada una de las seis variables dependientes

\begin{tabular}{|c|c|c|c|c|c|c|c|}
\hline & & $\begin{array}{l}\text { Afectó mi } \\
\text { avance } \\
\text { académi- } \\
\text { co y mi } \\
\text { proceso } \\
\text { de forma- } \\
\text { ción }\end{array}$ & $\begin{array}{c}\text { Me } \\
\text { resultó } \\
\text { más } \\
\text { difícil } \\
\text { aprender }\end{array}$ & $\begin{array}{c}\text { Me } \\
\text { generó } \\
\text { mayor } \\
\text { estrés }\end{array}$ & $\begin{array}{c}\text { Me } \\
\text { generó } \\
\text { nuevos } \\
\text { gastos } \\
\text { (inter- } \\
\text { net, } \\
\text { equipo) }\end{array}$ & $\begin{array}{c}\text { Me } \\
\text { deman- } \\
\text { da más } \\
\text { tiempo } \\
\text { que la } \\
\text { moda- } \\
\text { lidad } \\
\text { presen- } \\
\text { cial }\end{array}$ & $\begin{array}{c}\text { Me } \\
\text { deman- } \\
\text { da un } \\
\text { mayor } \\
\text { esfuer- } \\
\text { zo }\end{array}$ \\
\hline \multirow{2}{*}{$\begin{array}{l}\text { Significación } \\
\text { aproximada }\end{array}$} & $\begin{array}{l}\text { Coeficiente de } \\
\text { contingencia }\end{array}$ & 0.000 & 0.000 & 0.000 & 0.000 & 0.000 & 0.000 \\
\hline & Gamma & 0.037 & 0.003 & 0.000 & 0.000 & 0.000 & 0.000 \\
\hline
\end{tabular}

Fuente: elaboración propia. 
La figura 8 muestra la manera en que las seis variables arrojan una media mayor en los estudiantes con discapacidad que en el resto de los estudiantes.

Figura 8. Representación gráfica del cruce de la variable "discapacidad" con las seis variables dependientes mediante la comparación de medias

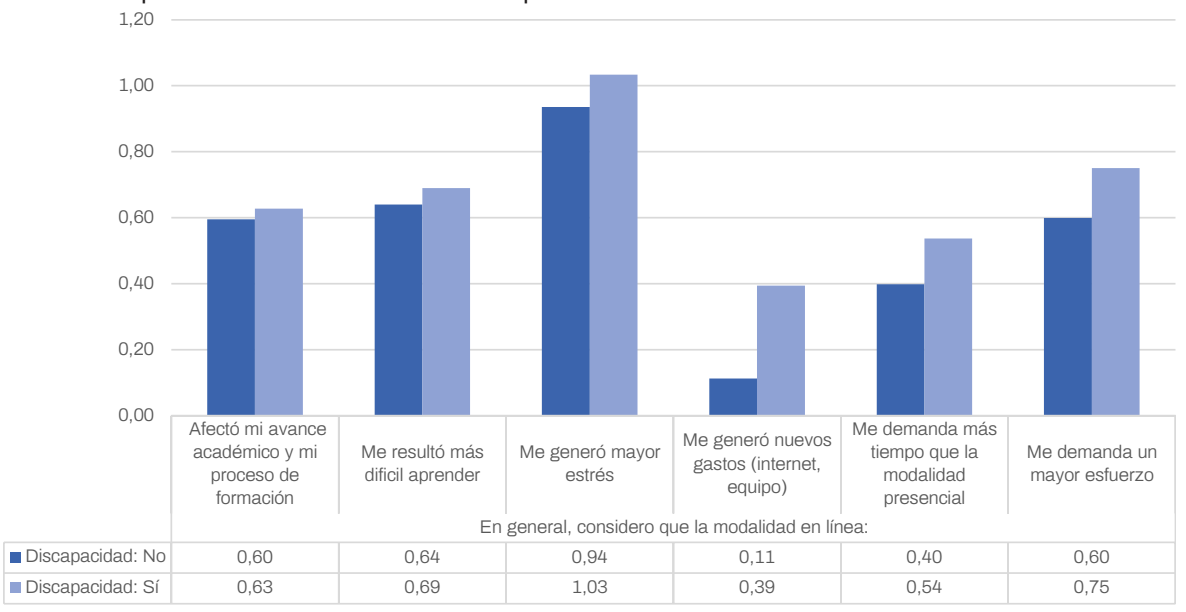

Fuente: elaboración propia.

Si bien en todas las variables la media de los estudiantes con discapacidad supera la media del resto de los estudiantes, la diferencia es mayor en las últimas cuatro variables. El grado de estrés que sufren es evidente al llegar a una media de 1.03 y lo mismo sucede con la variable "me generó nuevos gastos" que llega a 0.39 , marcando una distancia de 28 centésimas más que el resto de los estudiantes. La variable sobre la mayor demanda de tiempo muestra una diferencia de 14 centésimas y la de demanda de esfuerzo de 15 en comparación con los demás, las cuales llegan a 0.54 y 0.75 respectivamente. Los datos muestran un alto grado de vulnerabilidad de los estudiantes con discapacidad en el contexto de la pandemia.

\subsection{Nivel socioeconómico}

Para medir la manera en que estas diferencias sociales implicaron diferencias en los efectos de la pandemia en los estudiantes, era preciso construir una variable que dé cuenta del nivel socioeconómico de los estudiantes. Frente a la gran complejidad que esto representa y en torno a la cual se han construido diversos índices y mecanismos para lograrlo, para efectos de este estudio y con todas las limitaciones que pueda tener, se recurrió a la misma subjetividad de los estudiantes en relación a la autodefinición del nivel socioeconómico al que pertenecen. Bajo esta lógica el $51.9 \%$ de los estudiantes se considera de nivel medio, seguido por el $35.3 \%$ que se consideran de nivel medio bajo. En menor proporción se encuentran los estudiantes que se clasifican como nivel bajo (8.1\%) y solo un $4.5 \%$ como nivel medio alto y un $0.2 \%$ como nivel socioeconómico alto. 
Tabla 13. Frecuencias y porcentaje de respuestas por nivel socioeconómico

\begin{tabular}{lcc}
\hline & Frecuencia & Porcentaje \\
\hline Bajo & 8413 & 8.1 \\
Medio bajo & 36780 & 35.3 \\
Medio & 54049 & 51.9 \\
Medio alto & 4645 & 4.5 \\
Alto & 254 & 0.2 \\
Total & 104141 & 100 \\
\hline
\end{tabular}

Las pruebas de significancia se encuentran todas en un 0.000 lo que indica la fuerte relación existente entre las variables.

Tabla 14. Nivel de significancia del cruce de la variable "nivel socioeconómico" con cada una de las seis variables dependientes

\begin{tabular}{|c|c|c|c|c|c|c|c|}
\hline & & $\begin{array}{c}\text { Afectó } \\
\text { mi avan- } \\
\text { ce aca- } \\
\text { démico } \\
\text { y mi } \\
\text { proceso } \\
\text { de for- } \\
\text { mación }\end{array}$ & $\begin{array}{c}\text { Me } \\
\text { resultó } \\
\text { más } \\
\text { difícil } \\
\text { aprender }\end{array}$ & $\begin{array}{c}\text { Me } \\
\text { generó } \\
\text { mayor } \\
\text { estrés }\end{array}$ & $\begin{array}{c}\text { Me } \\
\text { generó } \\
\text { nuevos } \\
\text { gastos } \\
\text { (internet, } \\
\text { equipo) }\end{array}$ & $\begin{array}{c}\text { Me } \\
\text { deman- } \\
\text { da más } \\
\text { tiempo } \\
\text { que la } \\
\text { moda- } \\
\text { lidad } \\
\text { presen- } \\
\text { cial }\end{array}$ & $\begin{array}{c}\text { Me } \\
\text { deman- } \\
\text { da un } \\
\text { mayor } \\
\text { esfuerzo }\end{array}$ \\
\hline \multirow{2}{*}{$\begin{array}{l}\text { Significación } \\
\text { aproximada }\end{array}$} & $\begin{array}{l}\text { Coeficiente de } \\
\text { contingencia }\end{array}$ & 0.000 & 0.000 & 0.000 & 0.000 & 0.000 & 0.000 \\
\hline & Gamma & 0.000 & 0.000 & 0.000 & 0.000 & 0.000 & 0.000 \\
\hline
\end{tabular}

Fuente: elaboración propia.

Figura 9. Representación gráfica del cruce de la variable "nivel socioeconómico" con las seis variables dependientes mediante la comparación de medias

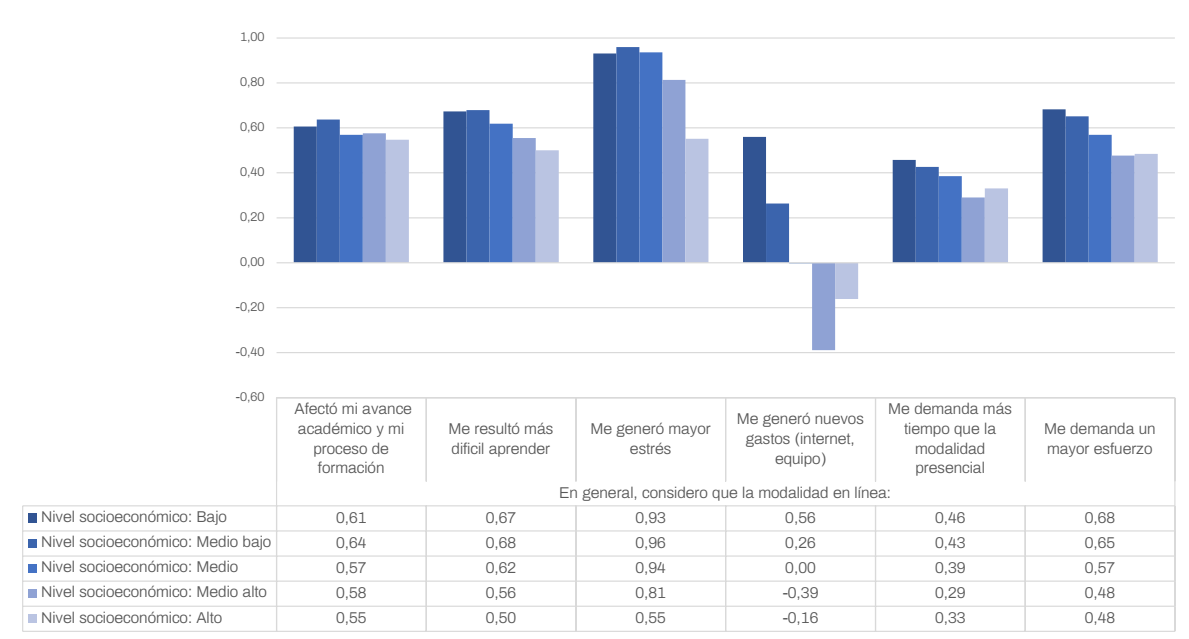

Fuente: elaboración propia. 
Las seis variables muestran una relación negativa, conforme aumenta al nivel económico disminuye el nivel de afectación en los estudiantes. Destaca en primer lugar la variable "me generó nuevos gastos", en la cual la media se torna negativa tanto en los niveles socioeconómicos "medio altos" como en los "altos". También la variable "me generó mayor estrés" marca una gran diferencia entre los diferentes estratos al llegar al 0.93 en el nivel bajo en contraste con un 0.55 en el nivel alto.

Las percepciones sobre la demanda de tiempo y esfuerzo, al igual que las anteriores, impactan en menor medida a las clases altas y lo mismo ocurre con la variable "me resultó más difícil aprender". Aún la variable "afectó mi avance académico" que reportó la brecha menor entre las clases altas y bajas, es bastante significativa.

\section{Discusión}

La implementación y puesta en práctica de los cursos a través de plataformas tecnológicas sin una planeación previa y con la gran premura que representó la transición, generó efectos de diversa índole en los estudiantes. Situación que se complejizó considerando las condiciones de aislamiento y restricciones que impuso la pandemia, condiciones que impactan de diferente forma a la diversidad de estudiantes. Frente a las grandes posibilidades de interpretación que arrojan los datos pondremos énfasis en algunos factores de vulnerabilidad que se hacen evidentes, así como en algunas áreas de oportunidad que se vislumbran.

Un importante factor de vulnerabilidad, aún en la actualidad, sigue siendo el género. Si bien las mujeres representan un importante porcentaje de la población en las Instituciones de Educación Superior IES, que supera incluso en algunos países latinoamericanos al de los hombres, es preciso recordar los obstáculos que históricamente han tenido para acceder a la educación (Mingo, 2006). Las condiciones de género construidas socioculturalmente ponen a las mujeres en situación de desventaja en relación al género opuesto. Las responsabilidades familiares y del hogar y en general la carga social atribuida a la naturaleza de su género, hacen que las mujeres enfrenten sus metas educativas en situación de desventaja con respecto a los hombres. Situación de desventaja que se vio reflejada en el estudio, en el que la mayoría de las variables hicieron evidentes importantes brechas de género. Aunque encontramos que el avance académico y el proceso de formación de las mujeres, fue la única variable en la que las afectaciones no superan a las de los hombres, al parecer el costo de ello fue afrontar mayores dificultades, como una mayor demanda de tiempo y un mayor esfuerzo, demandas que detonaron un marcado aumento del estrés que se manifestó notoriamente más en las mujeres que en los hombres.

Otros factores de vulnerabilidad son pertenecer a un pueblo indígena, tener alguna discapacidad y tener un bajo nivel económico. Éste último íntimamente correlacionado con los dos anteriores. Tanto para quienes pertenecen a un pueblo indígena, como para quienes tienen una discapacidad fue bastante significativo el problema de la generación de nuevos gastos en el contexto de la pandemia. Estas condiciones de vulnerabilidad han marcado históricamente diferencias que se ven reflejadas al interior de las instituciones educativas. Además de la exclusión que sufren gran parte de los ciudadanos al no tener acceso a la educación, existen otro tipo de problemáticas que enfrentan los individuos que forman parte del estudiantado. Bourdieu definió estas 
problemáticas menos evidentes, pero que marcan diferencias en el rendimiento y en las condiciones de los estudiantes, como formas ocultas de la desigualdad en educación, las cuales se agravan cuando los mecanismos que definen el éxito de los estudiantes en los sistemas educativos no hacen otra cosa que reproducir los mecanismos sociales de "elección de los elegidos" (Bourdieu, 2003; Bourdieu y Passeron, 2001).

Por otro lado, es importante encontrar las áreas de oportunidad de esta experiencia. La suspensión de las clases presenciales y la implementación de estrategias mediadas por tecnologías afectó en menor medida a ciertos estudiantes. Entre ellos se encuentran aquellos que tienen fuerte carga laboral, quienes manifiestan haber sido afectados en menor medida por el estrés, y en concordancia con esto, perciben menor demanda de tiempo y esfuerzo. Una situación similar la encontramos con el estado civil. La percepción de los estudiantes solteros es marcadamente diferente de la percepción de los estudiantes casados, en unión libre, viudos o divorciados. Los estudiantes solteros son más sensibles a las afectaciones provocadas por los cambios en el contexto de la pandemia que los estudiantes que tienen o han tenido un compromiso de pareja. La misma percepción la manifiestan los estudiantes que no tienen (o tienen pocos) dependientes económicos que, al igual que los solteros, perciben mayores afectaciones en ciertas variables como son las de avance académico y las de dificultades de aprendizaje.

Las inferencias que surgen de esta situación es que existe una relación entre el nivel de compromisos que tienen los estudiantes más allá del estudio y su percepción sobre los efectos de los cambios provocados por la pandemia. A mayores compromisos externos menores son las afectaciones percibidas. Esto pudiera atribuirse al grado de madurez de los estudiantes al tener o haber tenido compromisos de pareja, laborales o dependientes económicos, que les permiten encontrar las ventajas de la suspensión de la presencialidad y las bondades de las clases en línea y con ello, adaptarse de mejor manera.

Lo anterior nos invita a analizar las bondades latentes de la virtualidad y buscar las áreas de oportunidad que pudieran impulsar prospectivamente nuevas modalidades educativas. Por ejemplo, llama la atención algunas afectaciones que percibieron en menor medida los estudiantes indígenas que los no indígenas, como es el caso de la variable "me resultó más difícil aprender", así como la variable relacionada con el estrés. Es preciso comprender hasta dónde son rutas de oportunidad que nos lleven generar mecanismos de inclusión educativa apoyadas en tecnologías.

\section{Conclusiones}

Los últimos años se caracterizan por un aceleramiento en la transformación del contexto que rodea la realidad educativa, un aceleramiento que llegó a su máxima expresión con motivo de la pandemia. Este cambio de contexto demanda respuestas, "un cambio de contexto debería también corresponder a un cambio en la educación" (Prawda, 2005, p. 87), un cambio que debe estar orientado a la solución de problemáticas complejas que no surgen en el contexto de la pandemia, sino que existían previamente y que los modelos de desarrollo no han logrado solucionar. Las respuestas 
no pueden ser las mismas que tradicionalmente no han resuelto las complejas problemáticas. Albert Einstein dijo: "si tienes deseos de cambio, no puedes seguir haciendo lo mismo" (Delgado, 2020, p. 185).

Es importante aprovechar los aspectos positivos de la crisis, que, como toda crisis, ha roto esquemas, prácticas y tradiciones que en otros contextos hubiera sido difícil o imposible transformar. Sin duda nos encontramos en un momento de cambio, "hoy la universidad está movilizada y en estado de alerta. Se trata de un hecho histórico que ha generado una vigorosa sinergia entre instituciones de todas las geografías y todas las identidades políticas" (Casanova, 2020, p. 11). Es preciso aprovechar este momento de cambio para, dentro de todos los estragos causados por esta crisis, buscar nuevas soluciones para viejos problemas. La IES tienen el reto de recuperar los aprendizajes que brinda la experiencia y para ello es importante poner atención en las oportunidades de aprender de los diferentes actores educativos, entre los que los estudiantes, ocupan un lugar central. Sin embargo, estos aprendizajes no tendrán el mismo impacto si no se entretejen y vinculan con las diversas funciones sustantivas de la universidad. Es necesario generar sinergias entre la generación de conocimiento, la docencia y la extensión (Reimers et al., 2021), que potencien los alcances de los aprendizajes generados. Esto es, movilizar el conocimiento para lograr mayores posibilidades de solucionar los retos de desarrollo e inclusión social (Castellanos et al., 2019; Pérez-Mora et al., 2016)

Mucho se ha hablado del potencial de las tecnologías como un aliado de los procesos de enseñanza aprendizaje. Sin embargo, las tecnologías no son en sí mismas la solución si no se cuenta con las herramientas conceptuales, pedagógicas, metodológicas y técnicas para hacer de la tecnología un aliado estratégico en la tarea educativa.

\section{Referencias}

Beristain, J. (2005). Educación, crecimiento y desigualdad económica. En Educación y desigualdad (1. ${ }^{a}$ ed., pp. 39-52). Siglo XXI Editores S.A. de C.V.

Bourdieu, P. (2003). Los Herederos. Los estudiantes y la cultura. Siglo XXI Editores.

Bourdieu, P. y Passeron, J.-C. (2001). La reproducción. Elementos para una teoría del sistema de enseñanza (1. ${ }^{\mathrm{a}}$ ed.). Editorial Popular.

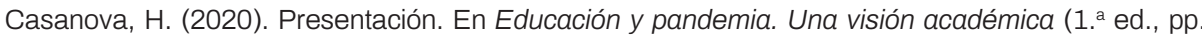
10-17). IISUE UNAM.

Castellanos, J. A., Pérez-Mora, R.y Becerra, J. A. (2019). La universidad en la movilización del conocimiento para la inclusión social. EccoS, 49(enero-julio), 1-18. https://doi.org/10.5585/ EccoS.n49.13334

Castellanos, J. A., Pérez-Mora, R., Carrillo, J. C. y Prieto, M. T. (2015). Estudiantes de la zona norte de Jalisco y Sur de Zacatecas. Un sujeto complejo desde diversas miradas (1. ${ }^{\mathrm{a}}$ ed.). Universidad de Guadalajara.

Delgado, G. (2020). Igualdad educativa y postpandemia. En Educación y pandemia. Una visión académica (1. ${ }^{\text {a }}$ ed., pp. 183-194). UNAM /IISUE.

Foucault, M. (2002). Vigilar y castigar. Nacimiento de la prisión. Siglo XXI editores.

Mingo, A. (2006). ¿Quién mordió la manzana? Sexo, origen social y desempeño en la Universidad (1. ${ }^{\mathrm{a}}$ ed.). UNAM / FCE. 
Pérez-Mora, R., García, O. y Ortíz, V. (2016). La movilización del conocimiento para la innovación social. Revista Eletrônica Pesquiseduca, 8(16), 277-294.

Prawda, J. (2005). Educación y desigualdad. En F. Solana (Ed.), Educación y desigualdad (1. ${ }^{\mathrm{a}}$ ed., pp. 87-107). Siglo XXI Editores S.A. de C.V.

Reimers, F. M., Amaechi, U., Banerji, A., \& Wang, M. (2021). Can universities and schools learn together? Connecting research, teaching and outreach to sustain educational opportunity during a pandemic. En F. M. Reimers, U. Amaechi, A. Banerji, \& M. Wang (Eds.), An educational calamity Learning and teaching during the Covid-19 pandemic (1. ${ }^{a}$ ed., p. 203). Recuperado de https://bit.ly/3hTBiR6

UNESCO. (2021). Impacto de la COVID-19 en la educación. Seguimiento mundial de los cierres de escuelas causados por el COVID-19. Recuperado de https://bit.ly/3xW7etl

Cómo citar este artículo en APA:

Pérez-Mora, R. y Moreno, C. I. (2021). Percepciones de los estudiantes, desde su diversidad, sobre los efectos de la transición a la modalidad en línea en el marco de la pandemia COVID-19. Revista Iberoamericana de Educación, 86(2), 147-169 https://doi.org/10.35362/rie8624444 